\title{
Exploring private land conservation non-adopters' attendance at outreach events in the Chesapeake Bay watershed, USA
}

\author{
Daniel Read $^{\text {Corresp., } 1}$, Alexandra Carroll ${ }^{1}$, Lisa Wainger ${ }^{1}$ \\ ${ }^{1}$ Chesapeake Biological Laboratory, University of Maryland Center for Environmental Science, Solomons, Maryland, United States of America \\ Corresponding Author: Daniel Read \\ Email address: dread@umces.edu
}

Background: Outreach events such as trainings, demonstrations, and workshops are important opportunities for encouraging private land operators to adopt voluntary conservation practices. However, the ability to understand the effectiveness of such events at influencing conservation behavior is confounded by the likelihood that attendees are already interested in conservation and may already be adopters. Understanding characteristics of events that draw non-adopters can aid in designing events and messaging that are better able to reach beyond those already interested in conservation.

Methods: For this study, we interviewed 101 operators of private agricultural lands in Maryland, USA, and used descriptive statistics and qualitative comparative analysis to investigate differences between the kinds of outreach events that adopters and non-adopters attend.

Results: Our results suggested that non-adopters, as compared to adopters, attended events that provided production-relevant information and were logistically easy to attend. Further, non-adopters were more selective when reading advertisements, generally preferring simplicity. Future research and outreach can build on these findings by experimentally testing the effectiveness of messages that are simple and relevant to farmers' production priorities. 
1 EXPLORING PRIVATE LAND CONSERVATION NON-

2 ADOPTERS' ATTENDANCE AT OUTREACH EVENTS

3 IN THE CHESAPEAKE BAY WATERSHED, USA

4

5

6

7

8

9

10

11

12

13

14

15

16

17

18

19

20

21

22

23

24

25

26

27

28

29

30

31

32

33

34

35

36

37

38

39

40

41

Daniel J. Read ${ }^{1}$, Alexandra Carroll ${ }^{1}$, Lisa Wainger ${ }^{1}$

${ }^{1}$ Chesapeake Biological Laboratory, University of Maryland Center for Environmental Science, Solomons, Maryland, USA

Corresponding Author:

Daniel J. Read ${ }^{1}$

146 Williams Street, Solomons, Maryland, 20688, USA

Email address: dread@umces.edu

\section{Abstract}

Background: Outreach events such as trainings, demonstrations, and workshops are important opportunities for encouraging private land operators to adopt voluntary conservation practices. However, the ability to understand the effectiveness of such events at influencing conservation behavior is confounded by the likelihood that attendees are already interested in conservation and may already be adopters. Understanding characteristics of events that draw non-adopters can aid in designing events and messaging that are better able to reach beyond those already interested in conservation.

Methods: For this study, we interviewed 101 operators of private agricultural lands in Maryland, USA, and used descriptive statistics and qualitative comparative analysis to investigate differences between the kinds of outreach events that adopters and non-adopters attend. Results: Our results suggested that non-adopters, as compared to adopters, attended events that provided production-relevant information and were logistically easy to attend. Further, nonadopters were more selective when reading advertisements, generally preferring simplicity. Future research and outreach can build on these findings by experimentally testing the effectiveness of messages that are simple and relevant to farmers' production priorities.

\section{Introduction}

Outreach events are important venues for educating communities about, and encouraging enrollment in, conservation practices and programs (Hall \& Fleishman 2010). Such events are especially important for advancing conservation on private working lands, where many programs rely on agricultural producers voluntarily adopting practices that may add costs to their operations (Lichtenberg 2004; Kamal et al. 2015; Capano et al. 2019; Sketch et al. 2020). In such situations, conservation practitioners routinely host trainings, demonstrations, field visits, and workshops to provide producers with information about how incorporating conservation 
42 practices will affect their operation (Miller et al. 2008; Genskow 2012; Christianson et al. 2014;

43

44

45

46

47

48

49

50

51

52

53

54

55

56

57

58

59

60

61

62

63

64

65

66

67

68

69

70

71

72

73

74

75

76

77

78

79

80

81

82

83

84

85 Starr et al. 2015; Zeweld et al. 2017).

Implementing conservation practices on private working lands can produce a number of environmental benefits (Swinton et al. 2007; Kremen \& Merenlender 2018). These diverse practices, ranging from stream restoration to minimal tillage, can reduce soil erosion and nutrient and sediment runoff, enhance wildlife habitat, and sequester carbon (GonzálezSánchez et al. 2012; García et al. 2016; Lee et al. 2020), though with varying effectiveness (Osmond et al. 2012). Individuals' reasons for whether to adopt these practices differ across several indicators, including their perceptions of how conservation practices will affect yields, their available capital and time to invest in the practice, and their environmental attitudes and levels of education (Liu et al. 2018; Dessart et al. 2019; Prokopy et al. 2019; Ranjan et al. 2019). In response to these diverse motivations and barriers, practitioners and policy-makers use numerous techniques, including financial incentives, social marketing campaigns, and outreach events, to encourage individuals to adopt conservation practices (Piñeiro et al. 2020).

Recent field experiments have tested how different attributes of outreach events contribute to their effectiveness at promoting the voluntary adoption of conservation practices. Varying the distance of outreach events from participants' locale can expand attendees' advice-sharing networks and increase likelihood of adopting conservation practices (Matous \& Todo 2018). Adding public commitment-making and other microinterventions to outreach events has also been shown to motivate some attendees to coordinate with and recruit more neighbors to participate in conservation programs on private lands (Niemiec et al. 2019). However, assessments of the effectiveness of outreach events are confounded by the potential for sampling bias, in that those attending events are likely to already be interested in conservation (Singh et al. 2018). Thus, to ensure that such events are reaching new audiences, there is a need to understand what motivates the attendance of individuals who are less likely to adopt voluntary conservation practices.

Conservation messaging research has explored similar questions about how to motivate people's participation in conservation (Kidd et al. 2019). Yet results from such studies may not be directly applicable to the intermediate step of increasing attendance by non-adopters at outreach events. Here, we define non-adopters as those individuals who have not adopted any of a set of conservation practices for which they are eligible (see below). Many messaging studies test interventions drawn from behavioral economics and nudge theory (Thaler \& Sunstein 2008; Byerly et al. 2018), such as positive versus negative framing (Jacobson et al. 2019), information about social norms (Byerly et al. 2019), and appeals to empathy (Czap et al. 2019), among others. However, among those studies that measure behavioral outcomes, the dependent variable is often whether respondents request further information (e.g. Dean et al. 2019; Reddy et al. 2020), which is a sufficiently different behavior from attending an outreach event to warrant caution in extrapolating findings. Further, the effectiveness of conservation messaging varies greatly, with no type of messaging intervention showing a consistent and significant direction of effect. 
86

87

88

89

90

91

92

93

94

95

96

97

98

99

100

101

102

103

104

105

106

107

108

109

110

111

112

113

114

115

116

117

118

119

120

121

122

123

124

125

126

127

128

129

Another limitation for applying conservation messaging research to reach non-adopters is that few studies have taken into account the production-orientation of many producers who operate private agricultural lands and are primarily motivated by increases in yields and income (but see Andrews et al. 2013; Reddy et al. 2020). In contrast to environmentally-oriented producers, production-oriented producers have few non-economic motives for adopting conservation. Such individuals are less likely to adopt practices that take land out of production, but may be interested in practices with short-term financial gains (Moon \& Cocklin 2011; Guillem et al. 2012; Daloğlu et al. 2014; Daxini et al. 2019; Upadhaya et al. 2021). While trust, identity, and other factors do influence adoption decisions, time-management, profits, and yields are overriding concerns, particularly among US agricultural producers (Osmond et al. 2012).

As a first step towards understanding what messages might motivate people with different propensities for conservation to attend outreach events, we conducted 101 phone interviews to learn how farmers in Maryland, USA, respond to advertisements for outreach events and what kind of outreach events they attend. In doing so, we aimed to address the question: How is the attendance of conservation non-adopters at outreach events influenced by characteristics of the producer, messaging, and the event? Our results suggested that non-adopters were much more selective in what advertisements they decided to read, and that they decided which events to attend largely based on the practicality of attending, in terms of logistics and whether they thought the information they would learn at the event would offset time and other costs.

\section{Materials \& Methods}

\section{Study site}

We conducted interviews with crop and livestock producers in Maryland, USA. Maryland farm production is diverse but, similar to much US cropland, is dominated by corn, soybean, wheat, and barley. Chickens are the dominant animals produced and the industry has undergone substantial consolidation over the past 20 years (USDA 2017; DCA 2021). Maryland differs from other regions by having a relatively small average farm size of 160 acres compared to the national average of 441 acres. Agricultural lands in Maryland face pressure from urbanization. Land cover data developed by USGS suggests a median loss of $9 \%$ of farmland in Maryland counties between 1983-2013, with a few counties experiencing losses of about 11,000-13,000 acres over this period (Irani \& Claggett 2017). Similarly, USDA data suggest that between 19972017, the number of farms in Maryland declined by about $6 \%$ (USDA 2017).

Rates of adoption for agricultural conservation practices, particularly cover crops, are relatively high in Maryland (Wallander et al. 2021). This high adoption rate is largely due to decades of effort to reduce nutrient runoff to the Chesapeake Bay, which is a eutrophic estuary and the receiving water body for most of Maryland's agricultural land. To reduce agricultural nutrient runoff, Maryland has passed regulations and expanded cost-share programs (Fleming 2017), including substantially higher payments for some cover crops in comparison to other states in the watershed (Bowman \& Lynch 2019). Additionally, a diverse array of county, state, and federal agencies, and non-profit organizations, host events that include one-hour webinars, farm tours, and annual conferences or workshops. These events complement other outreach initiatives, such as one-on-one farm visits, mentorship programs, and mass media 
130

131

132

133

134

135

136

137

138

139

140

141

142

143

144

145

146

147

148

149

150

151

152

153

154

155

156

157

158

159

160

161

162

163

164

165

166

167

168

169

170

171

172

173

communications, which are aimed at encouraging the adoption of voluntary agricultural conservation practices.

Improving the effectiveness of outreach efforts at engaging new audiences is crucial to achieving further conservation practice implementation and water quality goals. Water quality monitoring suggests that agriculture remains the largest contributor of nonpoint source nutrient runoff into the Chesapeake Bay and that such runoff has not substantially declined over the past thirty years (Ator et al. 2020). This lack of substantial decline in agricultural nutrient runoff makes understanding how to reach non-adopters particularly important to future restoration initiatives in the Chesapeake Bay watershed.

\section{Data Collection}

We conducted phone interviews between September-November 2020 with farmers selected to represent diverse production types. We constructed a sampling frame using several public directories from county and regional websites that connect producers and consumers (Supplementary Material). Because these directories overrepresented vegetable farmers, we also sampled farmers using a publicly available farm subsidy database (Environmental Working Group 2020). Using this database, we randomly selected two individuals per county, one who had received a corn subsidy and one who had received a soybean subsidy. We selected these individuals using a random number generator to select an initial farmer on the list, and then randomly moved up or down the list until we selected a farmer whose contact information was available online.

We used multiple email and phone contacts to collect responses. If we had an email address, we sent an initial email and followed up with a second email if we did not receive a reply after one week (Supplementary Material). We then called remaining non-respondents by phone and left a callback number on voice message if no one answered (Dillman et al. 1976; Vogl et al. 2019). If we did not have an email address, we called farmers, leaving a voice message if no one answered. If we did not receive a reply after one week, we called a second time and left another voice message. We excluded any respondent who also worked for conservation organizations like the USDA Natural Resources Conservation Service (NRCS), soil and water conservation districts (SWCD), university extension, or a non-profit conservation organization.

During the interviews, we asked respondents about their operation, their use of conservation practices, and whether they attended any outreach events in 2019. If they had, we asked about attributes of the most recent event they attended, including what it was about, who organized it, how they heard about it, and what their motivations were for attending. If they reported not attending any outreach events, we asked them if they had seen any advertised, and if so, why they chose not to attend and what might motivate them to attend events in the future (Supplementary Material). We pre-tested our questionnaire with four farmers in Virginia, the state directly south of Maryland, and made slight changes to the question order and wording before administering the interviews in Maryland. All respondents gave verbal informed consent to participate in this study and the University of Maryland, College Park Institutional Review Board approved all data collection procedures (\#1524456).

Peer) reviewing PDF | (2021:05:61360:1:0:REVIEW 14 Jul 2021) 
174

175

176

177

178

179

180

181

182

183

184

185

186

187

188

189

190

191

192

193

194

195

196

197

198

199

200

201

202

203

204

205

206

207

208

209

210

211

212

213

214

215

216

217

\section{Data Analysis}

With respondents' permission, we audio recorded the interviews and coded them using directed content analysis (Hsieh \& Shannon 2005; Bernard \& Ryan 2010). We created a codebook with possible responses for each question (Supplementary Material), and marked each code that the respondents mentioned as 1 , and all others as 0 . To assess intercoder reliability, each coder independently coded five interviews already coded by another coder, and we compared the two sets of codes by calculating Cohen's kappa (Cohen 1960). The resulting kappa value was 0.838 , indicating that the agreement between the coders was $83.8 \%$ better than expected by chance.

We analyzed the data and distinguished non-adopters from adopters using both descriptive statistics and qualitative comparative analysis (QCA; Basurto 2013; Pahl-wostl \& Knieper 2014; Brockhaus et al. 2017). QCA applies techniques from Boolean algebra and set theory to identify key combinations of conditions associated with an outcome (Ragin 1987; Rihoux 2003; Grofman \& Schneider 2009). It is particularly suitable for analyzing moderately-sized datasets that are too small for standard statistical techniques but too large for in-depth qualitative case study analysis (Ragin et al. 2003).

The codes from the content analysis formed the basis of the data calibration for QCA (note that QCA uses the terms 'conditions' and 'calibration' instead of 'variables' and 'coding,' respectively). We calibrated respondents as eligible for different conservation practices based on what they produced. If they produced livestock, we classified them as eligible for three livestock-related practices, and if they produced crops, we classified them as eligible for four crop-related practices (Table 1). We chose these practices because they are currently heavily promoted by policy-makers and staff from government and non-profit organizations in Maryland. Further, they apply to individual farming operations regardless of the physical landscape, allowing us to determine eligibility based on farm production characteristics alone.

\section{${ }^{* * * * *}$ INSERT TABLE 1 HERE ${ }^{* * * *}$}

Using these calibrations for eligibility, we then created two main outcome conditions that distinguished whether respondents were adopters or non-adopters and whether they reported attending at least one outreach event. Non-adopter attendees were those respondents who did not report adopting any of the conservation practices for which they were eligible and reported attending at least one outreach event. Adopter attendees were those who reported adopting at least one of the conservation practices for which they were eligible and reported attending at least one outreach event. We chose this restrictive definition of non-adoption, rather than considering practices individually, because we were particularly interested in understanding what kinds of events are attended by individuals who rarely interact with conservation practitioners. Adopting one conservation practice significantly increases the likelihood of adopting other complementary practices (Fleming 2017; Prokopy et al. 2019; Canales et al. 2020), thus effectively creating a subset of farmers who routinely interact with conservation practitioners. By classifying non-adopters as those who have not adopted any practices for 
218

219

220

221

222

223

224

225

226

227

228

229

230

231

232

233

234

235

236

237

238

239

240

241

242

243

244

245

246

247

248

249

250

251

252

253

254

255

256

257

258

259

260

261

which they are eligible, we aimed to distinguish those who rarely interact with conservation professionals from those who are likely to have more frequent interactions.

We calibrated 11 conditions related to characteristics of the respondent and their farm operation and 9 conditions related to characteristics of the most recent outreach event they attended (Table 2). We calibrated most conditions for the outreach events as multi-value by grouping together codes from the content analysis (Thiem 2015). We calibrated conditions related to the respondents and their farm operation largely as binary, retaining the original content analysis codes. However, we calibrated total acres as a multi-value condition, using quartiles as thresholds between values. We analyzed livestock and crop producers separately so that conditions about livestock did not apply to crop producers and vice versa. Accordingly, we used 7 conditions related to the respondent and their operation in each analysis.

\section{${ }^{* \star \star * \star}$ NSERT TABLE 2 HERE ${ }^{\star \star * \star *}$}

We transformed our calibrated data into truth tables and performed a logical minimization using the consistency cubes method (Dușa 2018) to produce the most parsimonious solution (Baumgartner \& Thiem 2020). A truth table is a reorganization of calibrated data, such that the columns represent the different conditions, each cell gets values from the calibrated data (0/1 for binary conditions, $0,1,2, \ldots$ for multi-value conditions), and there are as many rows as there are observed combinations of those conditions. Truth tables also include whether that row led to the outcome, and the number of observed cases corresponding to that row. The minimization of the truth table adheres to the following rule: if two combinations of conditions differ in only one condition yet produce the same outcome, then that condition can be considered irrelevant and removed to create a more simple expression (Ragin 1987:93). For example, if a non-adopter attended an evening event that was free, and another non-adopter attended an evening event that cost money, we would consider time of day to be a relevant condition, but cost an irrelevant condition, to describe the kinds of events non-adopters attend. The minimization process proceeds iteratively until the expression cannot be made more simple.

Because of the large number of conditions, we followed the two-step QCA procedure (Schneider 2019). The two-step procedure recognizes a difference between remote and proximate conditions, which are implicit in many social science analyses. Remote conditions are relatively stable over time and largely outside the reach of conscious influence. Proximate conditions vary over time and are subject to changes introduced by actors (Schneider \& Wagemann 2006). The two-step procedure begins by identifying necessary remote conditions that represent enabling contexts, and then includes those with the proximate conditions when minimizing the truth table (Schneider 2019).

In our analysis, we analyzed characteristics of the farmer and production as remote conditions and characteristics of the outreach events as proximate conditions. First, we identified remote conditions with consistency of necessity values above 0.9 and for which no deviant cases exist (cases including the condition but also the absence of the outcome). If no conditions meet that threshold, we assumed that remote conditions are not necessary for determining the outcome 
262

263

264

265

266

267

268

269

270

271

272

273

274

275

276

277

278

279

280

281

282

283

284

285

286

287

288

289

290

291

292

293

294

295

296

297

298

299

300

301

302

303

304

305

and proceeded with the parsimonious logical minimization of the proximate conditions. We evaluated our results using consistency and coverage of sufficiency scores. The former indicates the proportion of cases in which both the condition and outcome are present out of all instances of the condition, and the latter describes the same, but out of all instances of the outcomes (Ragin 2006). We conducted our analysis using the 'QCA' package (Dușa 2019) for $R$ statistical software (R Core Team 2020).

\section{Results}

\section{Descriptive Statistics}

We contacted 477 farmers and collected 101 valid responses for a response rate of $21.2 \%$. Eighty-one $(80.2 \%)$ respondents were eligible for crop-related conservation practices and 52 $(51.5 \%)$ were eligible for livestock-related conservation practices. Among the crop producers, 63 (77.8\%) reported attending at least one outreach event in 2019 and 5 of those individuals had not adopted any of the relevant crop-related conservation practices. Among livestock producers, $39(75 \%)$ reported attending at least one outreach event in 2019 and 4 of those individuals had not adopted any of the relevant livestock-related conservation practices. $23(22.8 \%)$ respondents reported not attending any outreach events in 2019.

These respondents were distributed across 19 of Maryland's 24 counties, and were more frequently concentrated in the north-central part of the state and less frequently in the lower Eastern Shore (Figure S1). The distribution of farm sizes within our sample was similar to that of Maryland overall, though with a slightly smaller proportion of small farms and higher proportion of vegetable growers (Table S1). Respondents most frequently reported producing 'Other crops,' which included mushrooms, emu, horses, fruits, and alpacas, followed by corn, hay, and beef cattle (Figure 1). Most respondents reported attending outreach events once every few months in 2019. Among those eligible for crop-related conservation practices, nearly $80 \%(\mathrm{~N}=$ $64)$ reported using cover crops and nearly $70 \%(\mathrm{~N}=54)$ reported using crop rotations. Among those eligible for livestock-related conservation practices, nearly $70 \%(\mathrm{~N}=37)$ reported using rotational grazing and over $50 \%(\mathrm{~N}=28)$ reported using stream exclusion fencing. Among both groups, the proportion of respondents reporting non-adoption of any eligible conservation practices was low.

\section{*****INSERT FIGURE 1 HERE*****}

Adopters and non-adopters reported important differences in how they filtered through event advertisements and how they considered which events to attend (Figure 2). Non-adopters were much more likely than adopters to report filtering advertisements based on whether the event was about what they produce on their farm and whether it was practical to attend the event. Practicality, in this sense, refers to whether the perceived cost in time spent away from the farm to attend the event would be compensated by the usefulness of the information they might learn by attending. For example, one non-adopter explained that she considers which events to attend based on which will give "the most bang for my buck or time." Adopters were much more likely than non-adopters to report not filtering the advertisements they received and looking at everything that came through their email inbox.

Peer) reviewing PDF | (2021:05:61360:1:0:REVIEW 14 Jul 2021) 
308

309

310

311

312

313

314

315

316

317

318

319

320

321

322

323

324

325

326

327

328

329

330

331

332

333

334

335

336

337

338

339

340

341

342

343

344

345

346

347

348

349

Similar to the responses of advertisement filtering, non-adopters who did not attend events cited practicality and applicability of event topics as reasons for not attending, while adopters had more wide ranging responses. Of the 101 respondents, only 5 had not adopted any conservation practices for which they were eligible and did not report attending any outreach events. They reported that the main reasons they did not attend events were the lack of applicable or interesting topics and the inconvenient timing of outreach events. All these respondents said that they would be more motivated to attend events that were nearby, short, and low to no cost to attend. Nineteen respondents had adopted at least one conservation practice for which they were eligible but did not report attending any outreach events. Of these, 9 said that they did not remember receiving, or have not received, advertisements for events. Others cited lack of internet access, inconvenient times, and event information being too simple as reasons for not attending. Ten non-attendee adopters said that they would or might attend future events, and suggested that more advanced event topics, guest speakers, online events online, and more convenient timing for in-person events would motivate them to attend.

\section{Qualitative Comparative Analysis}

We only included the proximate conditions (outreach event characteristics) in the logical minimization of the interview data because no remote conditions (farm characteristics) met the necessary inclusion criteria. Across all qualitative comparative analyses, no combination of remote conditions was both (1) associated with at least $90 \%$ of all instances of the outcome, and (2) not associated with any instances of the absence of the outcome. This finding held across all outcomes tested, indicating that remote conditions are not necessary for explaining whether an attendee was an adopter or non-adopter.

We identified three pathways associated with event attendees who had not adopted any livestock-related conservation practices, and six pathways for attendees who had adopted at least one such practice. Both the non-adopter and the adopter solutions fit the data well, with the consistencies both equal to 1.00 and the coverage equal to 1.00 and 0.914 , respectively (Figure 3).

The solution for non-adopters of livestock-related conservation practices who reported attending at least one outreach event is:

$$
N A_{\text {livestock }} \Leftrightarrow E D[2]^{*} W K[2]+M T[1]^{\star} E O[2]^{*} E D[3]+M T[5]^{\star} E O[1]^{*} E D[3]
$$

This solution should be read as: a non-adopter of livestock-based conservation practices will have reported attending an event if: (1) the event lasted 2-4 hours and occurred on the weekend, (2) they had multiple motivations for attending, the event was organized by county or university extension, and was all day, or (3) they were motivated by the event topic, the organizer was NRCS or SWCD, and it was all day. 
350

351

352

353

354

355

356

357

358

359

360

361

362

363

364

365

366

367

368

369

370

371

372

373

374

375

376

377

378

379

380

381

382

383

384

385

386

387

388

389

390

391

392

393

These individuals were characterized by attending events that they deemed to be worth the time away from their farms. The individual associated with the first pathway in Figure 3 said that her focus was on maintaining and improving practices, rather than adding more. She reported having issues with invasive weeds and said that any time she spends off-farm needs to be devoted to solving such issues. Similarly, the other three non-adopters all reported attending events that included hands-on training and demonstrations of particular practices by other farmers. One non-adopter said that she attends events that offer "a lot of practical advice that I [can] put to use right away." The individual associated with the third pathway in Figure 3 reported attending a farm tour that showcased a variety of livestock-related conservation practices. He emphasized that being able to see the practices implemented, and talk with those who use them was worth the time away from his own farm.

\section{*****INSERT FIGURE 3 HERE*****}

The solution for adopters of livestock-related conservation practices who reported attending at least one outreach event is:

$$
A_{\text {livestock }} \Leftrightarrow E O[4]+E D[1]+E D[4]+M T[1]^{*} E O[1]+M T[5]^{\star} E O[2]+E D[2]^{*} W K[1]
$$

This solution should be read as: an adopter of livestock-based conservation practices will have reported attending an event if: (1) it was organized by a private company or other group, (2) the event lasted 1-2 hours, (3) it was a multi-day event, (4) they had multiple motivations for attending and the event was organized by NRCS or SWCD, (5) they were motivated by the topic to attend and it was organized by a county or university extension, or (6) the event lasted 2-4 hours and occurred on a weekday.

We identified four pathways associated with event attendees who had not adopted any croprelated conservation practices and ten pathways for attendees who had adopted at least one such practice. Both the non-adopter and the adopter solutions fit the data reasonably well, with the consistencies both equal to one and the coverage equal to 0.714 and 0.875 , respectively (Figure 4)

The solution for non-adopters of crop-related conservation practices who reported attending at least one outreach event is:

$$
N A_{\text {crop }} \Leftrightarrow \mathrm{EO}[0]^{\star} \mathrm{CH}[3]+\mathrm{EA}[5]^{\star} \mathrm{ET}[2]+\mathrm{EO}[0]^{\star} \mathrm{EC}[2]+\mathrm{EO}[4]^{\star} \mathrm{EC}[2]^{\star} \mathrm{CH}[2]
$$

This solution should be read as: a non-adopter of crop-related conservation practices will have reported attending an event if: (1) they don't remember the organizer and received a paper advertisement about the event, (2) the most recent event they attended was about multiple topics and it started in the afternoon or evening, (3) they don't remember who organized the most recent event they attended and it cost money to attend, or (4) the event was organized by a private group, cost money, and was advertised online. 
394

395

396

397

398

399

400

401

402

403

404

405

406

407

408

409

410

411

412

413

414

415

416

417

418

419

420

421

422

423

424

425

426

427

428

429

430

431

432

433

434

435

436

437

Similar to the non-adopters of livestock-related practices, these individuals were characterized by attending events that directly related to their farm production and easy to attend. For example, the respondent associated with the third pathway in Figure 4 reported hesitating about whether to attend because he worried it would put him behind in terms of his production goals. He attended because the cost covered a meal and because he would have the opportunity to network with other farmers like him. He said that he prefers events on other local farms, where "you can, in-person, meet a couple people and not have to drive very far." Similarly, a respondent associated with the fourth pathway in Figure 4 reported attending an event to network and to stay familiar with industry trends. For him, the cost of attending a large trade show that enabled such networking was more than offset by the benefits it would yield to his production capabilities. The other respondent associated with the fourth pathway attended an event to stay up-to-date with manure regulations. All these respondents reported perceiving benefits of attending events that directly related to their farm production, and not to conservation generally.

The solution for adopters of crop-related conservation practices who reported attending at least one outreach event is:

$$
\begin{gathered}
\mathrm{A}_{\text {crop }} \Leftrightarrow \mathrm{MT}[4]+\mathrm{EO}[2]+\mathrm{EC}[1]+\mathrm{CH}[1]+\mathrm{MT}[5]^{\star} \mathrm{EA}[5]+\mathrm{MT}[5]^{*} \mathrm{CH}[0]+\mathrm{EO}[1]^{\star} \mathrm{EA}[4]+ \\
\mathrm{EO}[3]^{\star} \mathrm{EA}[3]+\mathrm{ET}[1]^{*} \mathrm{WK}[2]+\mathrm{ED}[3]^{\star} \mathrm{KO}[1]
\end{gathered}
$$

This solution should be read as: an adopter of crop-related conservation practices will have reported attending an event if: (1) they were motivated by a social aspect of the event, (2) the event was organized by county or university extension, (3) the event was free, (4) they helped organize the event, (5) they were motivated by the event topic and the event was about multiple topics, (6) they were motivated by the event topic and they don't remember how the event was advertised, (7) the event was organized by NRCS or a soil and water conservation district and the event was about conservation, (8) the event was organized by a non-profit and it was about agricultural land management, (9) the event was in the morning and on a weekend, or (10), the event was all day and they did not know other attending beforehand.

\section{*****INSERT FIGURE 4 HERE****}

\section{Discussion}

Our results suggested that non-adopters, more than adopters, based their attendance decisions on their perceptions of the ease of attending and whether the value of information learned will compensate for time taken away from the farm and out-of-pocket costs (cf. Wang et al. 2020). Three lines of evidence supported this finding. First, non-adopters more frequently reported filtering through event advertisements for those that appeared to be convenient to attend and about something they produced, whereas adopters more frequently reported no specific filter. This emphasis on practicality is consistent with previous research on producers' engagements with conservation (Greiner \& Gregg 2011; Jackson-Smith \& McEvoy 2011), and suggests that non-adopters' decisions to attend outreach events reflected a production-orientation. Second, among those who reported not attending any events, non-adopters' reasons for not attending 
438

439

440

441

442

443

444

445

446

447

448

449

450

451

452

453

454

455

456

457

458

459

460

461

462

463

464

465

466

467

468

469

470

471

472

473

474

475

476

477

478

479

480

481

were largely that the event topics were inapplicable or that the events were at inconvenient times and locations.

Third, the results from the QCA further supported our finding of a production-orientation among non-adopters. One finding from the QCA suggested that non-adopters were distinguished from adopters by preferring all-day events and weekend events. For livestock-related conservation practices, adopters attended 2-4 hour events on the weekday, while non-adopters attended 2-4 hour events on the weekend (Figure 3). Similarly, two non-adopter pathways including the condition that the event was all-day, while this condition was not in any adopter pathway. Respondents related the conditions of being all-day and on the weekend to how much production-relevant information they thought they would get out of the event. One non-adopter reported that he most recently attended an all-day farm tour that demonstrated several livestock-related practices. For him, the ability to see multiple relevant practices implemented and to talk to those implementing them was worth his time away from the farm. Likewise, the other non-adopters of livestock-related conservation practices suggested that they were motivated to attend events that provided hands-on training and allowed them to talk to farmers currently implementing these practices. These findings suggested that non-adopters preferred attending events that are long enough to ensure that they will learn enough information to make attendance worthwhile.

The results from the QCA also suggested that non-adopters attended events that cost money, while adopters gravitated towards free events. Among crop-related conservation practices, only adopters reported attending free events and the condition that the event cost money appeared in two non-adopter pathways. While cost poses a small barrier to attendance (respondents reported that admission was usually between \$10-35 USD for events with fees), the respondents indicated that this barrier was more than overcome by the ability to learn different types of production-relevant information. Many conferences and trade shows have entrance fees, but also allow attendees to meet with a variety of groups and individuals, enabling them to stay up-to-date on industry and regulatory trends. Farm tours tend to be all-day events in which the cost covers a meal and attendees get to see different practices implemented on others' farms and ask questions about them. In this sense, cost, as a characteristic of events attended by non-adopters, is associated with events that provided attendees the opportunity to network with other farmers and stay up-to-date on industry and regulatory trends. While some free events may provide the same information and networking opportunities, no respondents reported any free, in-person events on the weekend. As a result, cost, in our sample, may double as a proxy for non-adopters' preference for weekend events.

Apart from distinguishing non-adopters by their emphasis on attending practical, productionrelevant events, our results also showed some similarities between adopters and non-adopters. First, our analysis suggested that farmer and production characteristics were not necessary to distinguish the two groups. This finding largely agrees with the agricultural conservation adoption literature, which does not show consistent significant relationships between adoption rates and most farmer and production characteristics, with the exception of farm acreage and farmer age (Prokopy et al. 2019). Second, all respondents had similar motivations for attending 
482

483

484

485

486

487

488

489

490

491

492

493

494

495

496

497

498

499

500

501

502

503

504

505

506

507

508

509

510

511

512

513

514

515

516

517

518

519

520

521

522

523

524

525

outreach events. When respondents only had a single motivation for attending, in all cases but one they were motivated by the event topic. When respondents reported multiple motivations for attending, all non-adopters and $90 \%$ of adopters said that one of their motivations for attending was the event topic. Third, we found only minor differences in the effect of hosting organization adopters' and non-adopters' attendance across livestock and crop farms. NRCS, SWCD, extension, non-profits, and private groups all appeared in the pathways for adopters and nonadopters.

\section{Recommendations for Future Outreach}

Our exploratory results have several implications for the design of outreach events and conservation messaging to improve the likelihood of non-adopter attendance. Our results suggest that centering outreach messaging around production goals, rather than conservation, may encourage more non-adopters to attend events. More specifically, our results suggest that, to attract non-adopters, email subject lines should contain information that clarifies which production types can benefit from the practices being discussed. Further, scheduling events at convenient times with ample opportunity for farmer discussion may also encourage non-adopter attendance. Non-adopters sought in-depth information and hands-on training, as provided in allday or weekend events, and were willing to pay to attend events that included the ability to talk to other farmers and agricultural professionals about multiple topics for significant periods of time.

\section{Recommendations for Future Research}

Additional conservation messaging research could expand beyond our relatively small nonrandom sample and test generalizability. Our finding that farm production characteristics do not meaningfully distinguish whether event attendees are non-adopters suggests that our results about messaging and event content could apply across diverse farm types and geographies. However, safety precautions aimed at preventing the spread of COVID-19 meant that most inperson outreach events were cancelled during our research period. Future research could go beyond self-reported attendance and observe in-person events to understand how nonadopters' attendance varies by different event attributes.

More fundamentally, future work could explore how simplifying messages and emphasizing production priorities affects who attends outreach events. Our finding that non-adopters largely filter event advertisements only for relevance and practicality is consistent with messaging research that has found that greater simplicity of messages, typically measured as the amount of text or number of motivators addressed, can motivate behavior change (Farrow et al. 2018; John \& Blume 2018). Much conservation messaging research evaluates whether adding information or reframing how it is presented affects respondents' behavior (e.g. Chen et al. 2009; Byerly et al. 2019). Some of those studies have found that messages about increasing profits to be ineffective (Andrews et al. 2013; Reddy et al. 2020), which differs somewhat from our findings. More research is needed to examine how different production-oriented framings, such as specific production types and goals, affect people's responses to conservation messaging. Lastly, further research could examine how the number of times people are exposed to conservation messaging and the number and type of events they attend correlate

Peer) reviewing PDF | (2021:05:61360:1:0:REVIEW 14 Jul 2021) 
526

527

528

529

530

531

532

533

534

535

536

537

538

539

540

541

542

543

544

545

546

547

548

549

550

551

552

553

554

555

556

557

558

559

560

561

562

563

564

565

566

567

568

569

570

571

with the adoption of specific conservation practices, or other non-dichotomous behavioral outcomes (Pannell \& Claassen 2020).

\section{Conclusions}

Conservation messaging and outreach are more effective when they are constructed with knowledge of the social context within which they will be delivered (Byerly et al. 2019; Kusmanoff et al. 2020). Our findings from exploratory research with crop and livestock producers on private working lands in Maryland, USA support this idea and suggest that nonadopters of agricultural conservation practices used different criteria than adopters for choosing which outreach events to attend. Compared to adopters, non-adopters primarily attended outreach events that they thought would justify time taken away from the farm by providing them with production-relevant information. When filtering through event advertisements, they looked for events that were relevant to their production, convenient to attend, and that allowed ample time to talk with other farmers and agricultural professionals. We suggest that further experimental research examine the effect of simple productivity messaging and event structure on non-adopters' attendance and conservation practice adoption. Such research will help to design more effective advertisements and events that reach beyond those already interested in conservation and encourage those who have had limited engagement to explore further opportunities for adopting conservation practices.

\section{Acknowledgements}

We thank the respondents for generously offering their time and perspective. We declare no conflicts of interest.

\section{References}

Andrews, A.C., Clawson, R.A., Gramig, B.M. \& Raymond, L. (2013). Why do farmers adopt conservation tillage? An experimental investigation of framing effects. J. Soil Water Conserv., 68, 501-511.

Ator, S.W., Blomquist, J.D., Webber, J.S. \& Chanat, J.G. (2020). Factors driving nutrient trends in streams of the Chesapeake Bay watershed. J. Environ. Qual., 49, 812-834.

Basurto, X. (2013). Linking multi-level governance to local common-pool resource theory using fuzzy-set qualitative comparative analysis: Insights from twenty years of biodiversity conservation in Costa Rica. Glob. Environ. Chang., 23, 573-587.

Baumgartner, M. \& Thiem, A. (2020). Often Trusted but Never (Properly) Tested: Evaluating Qualitative Comparative Analysis. Sociol. Methods Res., 49, 279-311.

Bernard, H.R. \& Ryan, G.W. (2010). Analyzing Qualitative Data: Systematic Approaches. SAGE Publications, Inc., Thousand Oaks.

Bowman, M. \& Lynch, L. (2019). Government Programs that Support Farmer Adoption of Soil Health Practices: A Focus on Maryland's Agricultural Water Quality Cost-Share Program. Choices, 34, 1-8.

Bragina, L., Sherlock, O., van Rossum, A.J. \& Jennings, E. (2017). Cattle exclusion using fencing reduces Escherichia coli (E. coli) level in stream sediment reservoirs in northeast Ireland. Agric. Ecosyst. Environ., 239, 349-358.

Brockhaus, M., Korhonen-Kurki, K., Sehring, J., Di Gregorio, M., Assembe-Mvondo, S., Babon, A., Bekele, M., Gebara, M.F., Khatri, D.B., Kambire, H., Kengoum, F., Kweka, D., Menton, M., Moeliono, M., Paudel, N.S., Pham, T.T., Resosudarmo, I.A.P., Sitoe, A., Wunder, S. \& 
572

573

574

575

576

577

578

579

580

581

582

583

584

585

586

587

588

589

590

591

592

593

594

595

596

597

598

599

600

601

602

603

604

605

606

607

608

609

610

611

612

613

614

615

616

617

618

619

620

621

622
Zida, M. (2017). REDD+, transformational change and the promise of performance-based payments: a qualitative comparative analysis. Clim. Policy, 17, 708-730.

Byerly, H., Balmford, A., Ferraro, P.J., Wagner, C.H., Palchak, E., Polasky, S., Ricketts, T.H., Schwartz, A.J. \& Fisher, B. (2018). Nudging pro-environmental behavior: evidence and opportunities. Front. Ecol. Environ., 16, 159-168.

Byerly, H., D’Amato, A.W., Hagenbuch, S. \& Fisher, B. (2019). Social influence and forest habitat conservation: Experimental evidence from Vermont's maple producers. Conserv. Sci. Pract., 1, e98.

Canales, E., Bergtold, J.S. \& Williams, J.R. (2020). Conservation practice complementarity and timing of on-farm adoption. Agric. Econ., 51, 777-791.

Capano, G.C., Toivonen, T., Soutullo, A. \& Minin, E. Di. (2019). The emergence of private land conservation in scientific literature: A review. Biol. Conserv., 237, 191-199.

Chen, X., Lupi, F., He, G. \& Liu, J. (2009). Linking social norms to efficient conservation investment in payments for ecosystem services. Proc. Natl. Acad. Sci. U. S. A., 106, 11812-11817.

Christianson, L., Knoot, T., Larsen, D., Tyndall, J. \& Helmers, M. (2014). Adoption potential of nitrate mitigation practices: an ecosystem services approach. Int. J. Agric. Sustain., 12, 407-424.

Cohen, J. (1960). A coefficient of agreement for nominal scales. Educ. Psychol. Meas., XX, 3746.

Czap, N. V., Czap, H.J., Banerjee, S. \& Burbach, M.E. (2019). Encouraging farmers' participation in the Conservation Stewardship Program: A field experiment. Ecol. Econ., $161,130-143$.

Dabney, S., Delgado, J. \& Reeves, D. (2001). Using Winter Cover Crops to Improve Soil and Water Quality. Commun. Soil Sci. Plant Anal., 32, 1221-1250.

Daloğlu, I., Nassauer, J.I., Riolo, R.L. \& Scavia, D. (2014). Development of a farmer typology of agricultural conservation behavior in the American Corn Belt. Agric. Syst., 129, 93-102.

Daxini, A., Ryan, M., O’Donoghue, C., Barnes, A.P. \& Buckley, C. (2019). Using a typology to understand farmers' intentions towards following a nutrient management plan. Resour. Conserv. Recycl., 146, 280-290.

DCA. (2021). Delmarva Chicken Association Facts \& Figures [WWW Document]. URL https://www.dcachicken.com/facts/facts-figures.cfm

Dean, A.J., Fielding, K.S. \& Wilson, K.A. (2019). Building community support for coastal management — What types of messages are most effective? Environ. Sci. Policy, 92, 161169.

Dessart, F.J., Barreiro-Hurlé, J. \& Van Bavel, R. (2019). Behavioural factors affecting the adoption of sustainable farming practices: A policy-oriented review. Eur. Rev. Agric. Econ., 46, 417-471.

Dillman, D.A., Gallegos, J.G. \& Frey, J.H. (1976). Reducing refusal rates for telephone interviews. Public Opin. Q., 40, 66-78.

Dușa, A. (2018). Consistency Cubes: a fast, efficient method for exact Boolean minimization. $R$ J., 10, 357-370.

Dușa, A. (2019). QCA with R: A Comprehensive Resource. Springer International Publishing.

Environmental Working Group. (2020). Farm Subsidy Database [WWW Document]. URL https://farm.ewg.org/

Farrow, K., Grolleau, G. \& Mzoughi, N. (2018). Less is more in energy conservation and efficiency messaging. Energy Policy, 122, 1-6.

Fleming, K., Westfall, D., Wiens, D. \& Brodahl, M. (2000). Evaluating Farmer Defined Management Zone Maps for Variable Rate Fertilizer Application. Precis. Agric., 2, 201215.

Fleming, P. (2017). Agricultural Cost Sharing and Water Quality in the Chesapeake Bay: 
623

624

625

626

627

628

629

630

631

632

633

634

635

636

637

638

639

640

641

642

643

644

645

646

647

648

649

650

651

652

653

654

655

656

657

658

659

660

661

662

663

664

665

666

667

668

669

670

671

672

673

Estimating Indirect Effects of Environmental Payments. Am. J. Agric. Econ., 99, 12081227.

García, A.M., Alexander, R.B., Arnold, J.G., Norfleet, L., White, M.J., Robertson, D.M. \& Schwarz, G. (2016). Regional Effects of Agricultural Conservation Practices on Nutrient Transport in the Upper Mississippi River Basin. Environ. Sci. Technol., 50, 6991-7000.

Genskow, K. (2012). Taking stock of voluntary nutrient management: Measuring and tracking change. J. Soil Water Conserv., 67, 51-58.

González-Sánchez, E.J., Ordóñez-Fernández, R., Carbonell-Bojollo, R., Veroz-González, O. \& Gil-Ribes, J.A. (2012). Meta-analysis on atmospheric carbon capture in Spain through the use of conservation agriculture. Soil Tillage Res., 122, 52-60.

Greiner, R. \& Gregg, D. (2011). Farmers' intrinsic motivations, barriers to the adoption of conservation practices and effectiveness of policy instruments: Empirical evidence from northern Australia. Land use policy, 28, 257-265.

Grofman, B. \& Schneider, C. (2009). An Introduction to Crisp Set QCA, with a Comparison to Binary Logistic Regression. Polit. Res. Q., 62, 662-672.

Guillem, E.E., Barnes, A.P., Rounsevell, M.D.A. \& Renwick, A. (2012). Refining perceptionbased farmer typologies with the analysis of past census data. J. Environ. Manage., 110, 226-235.

Hall, J.A. \& Fleishman, E. (2010). Demonstration as a Means to Translate Conservation Science into Practice. Conserv. Biol., 24, 120-127.

Holland, J. (2004). The environmental consequences of adopting conservation tillage in Europe: reviewing the evidence. Agric. Ecosyst. Environ., 103, 1-15.

Hsieh, H.F. \& Shannon, S.E. (2005). Three approaches to qualitative content analysis. Qual. Health Res., 15, 1277-1288.

Irani, F. \& Claggett, P. (2017). Phase 6 Land Use [WWW Document]. Chesap. Bay Progr. URL https://www.chesapeakebay.net/who/group/land_use_workgroup

Jackson-Smith, D.B. \& McEvoy, J.P. (2011). Assessing the Long-Term Impacts of Water Quality Outreach and Education Efforts on Agricultural Landowners. J. Agric. Educ. Extension2, $17,341-353$.

Jacobson, S.K., Morales, N.A., Chen, B., Soodeen, R., Moulton, M.P. \& Jain, E. (2019). Love or Loss: Effective message framing to promote environmental conservation. Appl. Environ. Educ. Commun., 18, 252-265.

John, P. \& Blume, T. (2018). How best to nudge taxpayers? The impact of message simplification and descriptive social norms on payment rates in a central London local authority. J. Behav. Public Adm., 1, 1-11.

Kamal, S., Grodzińska-Jurczak, M. \& Brown, G. (2015). Conservation on private land: a review of global strategies with a proposed classification system. J. Environ. Plan. Manag., 58, 576-597.

Kidd, L.R., Garrard, G.E., Bekessy, S.A., Mills, M., Camilleri, A.R., Fidler, F., Fielding, K.S., Gordon, A., Gregg, E.A., Kusmano, A.M., Louis, W., Moon, K., Robinson, J.A., Selinske, M.J., Shanahan, D. \& Adams, V.M. (2019). Messaging matters: A systematic review of the conservation messaging literature. Biol. Conserv., 236, 92-99.

Kremen, C. \& Merenlender, A.M. (2018). Landscapes that work for biodiversity and people. Science (80-. )., 362, eaau6020.

Kusmanoff, A.M., Fidler, F., Gordon, A., Garrard, G.E. \& Bekessy, S.A. (2020). Five lessons to guide more effective biodiversity conservation message framing. Conserv. Biol., 34, 11311141.

Lee, S., McCarty, G.W., Moglen, G.E., Li, X. \& Wallace, C.W. (2020). Assessing the effectiveness of riparian buffers for reducing organic nitrogen loads in the Coastal Plain of the Chesapeake Bay watershed using a watershed model. J. Hydrol., 585, 124779.

Lichtenberg, E. (2004). Cost-Responsiveness of Conservation Practice Adoption: A Revealed

Peer) reviewing PDF | (2021:05:61360:1:0:REVIEW 14 Jul 2021) 
674

675

676

677

678

679

680

681

682

683

684

685

686

687

688

689

690

691

692

693

694

695

696

697

698

699

700

701

702

703

704

705

706

707

708

709

710

711

712

713

714

715

716

717

718

719

720

721

722

723

724

Preference Approach. J. Agric. Resour. Econ., 29, 420-435.

Liu, T., Bruins, R.J.F. \& Heberling, M.T. (2018). Factors influencing farmers' adoption of best management practices: A review and synthesis. Sustain., 10, 1-26.

Matous, P. \& Todo, Y. (2018). An experiment in strengthening the networks of remote communities in the face of environmental change: leveraging spatially distributed environmental memory. Reg. Environ. Chang., 18, 1741-1752.

Meals, D.W. \& Braun, D.C. (2006). Demonstration of Methods to Reduce E. coli Runoff from Dairy Manure Application Sites. J. Environ. Qual., 35, 1088-110.

Miller, M.J., Mariola, M.J. \& Hansen, D. (2008). EARTH to farmers: Extension and the adoption of environmental technologies in the humid tropics of Costa Rica. Ecol. Eng., 34, 349-357.

Moon, K. \& Cocklin, C. (2011). A Landholder-Based Approach to the Design of Private-Land Conservation Programs. Conserv. Biol., 25, 493-503.

Niemiec, R.M., Willer, R., Ardoin, N.M. \& Brewer, F.K. (2019). Motivating landowners to recruit neighbors for private land conservation. Conserv. Biol., 33, 930-941.

Osmond, D., Meals, D., Hoag, D., Arabi, M., Luloff, A., Jennings, G., McFarland, M., Spooner, J., Sharpley, A. \& Line, D. (2012). Improving conservation practices programming to protect water quality in agricultural watersheds: Lessons learned from the National Institute of Food and Agriculture-Conservation Effects Assessment Project. J. Soil Water Conserv., 67.

Pahl-wostl, C. \& Knieper, C. (2014). The capacity of water governance to deal with the climate change adaptation challenge: Using fuzzy set Qualitative Comparative Analysis to distinguish between polycentric, fragmented and centralized regimes. Glob. Environ. Chang., 29, 139-154.

Pannell, D.J. \& Claassen, R. (2020). The Roles of Adoption and Behavior Change in Agricultural Policy. Appl. Econ. Perspect. Policy, 42, 31-41.

Piñeiro, V., Arias, J., Dürr, J., Elverdin, P., Ibáñez, A.M., Kinengyere, A., Opazo, C.M., Owoo, N., Page, J.R., Prager, S.D. \& Torero, M. (2020). A scoping review on incentives for adoption of sustainable agricultural practices and their outcomes. Nat. Sustain., 3, 809820.

Prokopy, L.S., Floress, K., Arbuckle, J.G., Church, S.P., Eanes, F.R., Gao, Y., Gramig, B.M., Ranjan, P. \& Singh, A.S. (2019). Adoption of agricultural conservation practices in the United States: Evidence from 35 years of quantitative literature. J. Soil Water Conserv., 74, 520-534.

R Core Team. (2020). R: A language and environment for statistical computing.

Ragin, C. (1987). The Comparative Method: Moving Beyond Qualitative and Quantitative Strategies. University of California Press, Berkeley.

Ragin, C.C. (2006). Set Relations in Social Research: Evaluating Their Consistency and Coverage. Polit. Anal., 14, 291-310.

Ragin, C.C., Shulman, D., Weinberg, A. \& Gran, B. (2003). Complexity, Generality, and Qualitative Comparative Analysis. Field methods, 15, 323-340.

Ranjan, P., Church, S.P., Floress, K. \& Prokopy, L.S. (2019). Synthesizing Conservation Motivations and Barriers: What Have We Learned from Qualitative Studies of Farmers' Behaviors in the United States? Soc. Nat. Resour., 32, 1171-1199.

Reddy, S.M.W., Wardropper, C., Weigel, C., Masuda, Y.J., Harden, S., Ranjan, P., Getson, J.M., Esman, L.A., Ferraro, P. \& Prokopy, L. (2020). Conservation behavior and effects of economic and environmental message frames. Conserv. Lett., 13, e12750.

Rihoux, B. (2003). Bridging the Gap between the Qualitative and Quantitative Worlds? A Retrospective and Prospective View on Qualitative Comparative Analysis. Field methods, $15,351-365$.

Schneider, C.Q. (2019). Two-step QCA revisited: the necessity of context conditions. Qual. Quant., 53, 1109-1126.

Peer) reviewing PDF | (2021:05:61360:1:0:REVIEW 14 Jul 2021) 
725

726

727

728

729

730

731

732

733

734

735

736

737

738

739

740

741

742

743

744

745

746

747

748

749

750

751

752

753

754

755

756

757

758

759

760

761

762

Schneider, C.Q. \& Wagemann, C. (2006). Reducing complexity in Qualitative Comparative Analysis (QCA): Remote and proximate factors and the consolidation of democracy Introduction : QCA - An additional logic of social inquiry. Eur. J. Polit. Res., 45, 751-786.

Singh, A., MacGowan, B., O'Donnell, M., Overstreet, B., Ulrich-Schad, J., Dunn, M., Klotz, H. \& Prokopy, L. (2018). The influence of demonstration sites and field days on adoption of conservation practices. J. Soil Water Conserv., 73, 276-283.

Sketch, M., Dayer, A.A. \& Metcalf, A.L. (2020). Engaging Landowners in the Conservation Conversation through Landowner-Listening Workshops. Soc. Nat. Resour., 33, 669-680.

Sovell, L.A., Vondracek, B., Frost, J.A. \& Mumford, K.G. (2000). Impacts of Rotational Grazing and Riparian Buffers on Physicochemical and Biological Characteristics of Southeastern Minnesota, USA, Streams. Environ. Manage., 26, 629-641.

Starr, S.E., McConnell, T.E., Bruskotter, J.S. \& Williams, R.A. (2015). Typology of Ohio, USA, Tree Farmers Based Upon Forestry Outreach Needs. Environ. Manage., 55, 308-320.

Swinton, S.M., Lupi, F., Robertson, G.P. \& Hamilton, S.K. (2007). Ecosystem services and agriculture: Cultivating agricultural ecosystems for diverse benefits. Ecol. Econ., 64, 245252.

Thaler, R.H. \& Sunstein, C.R. (2008). Nudge: Improving Decisions About Health, Wealth, and Happiness. Yale University Press, New Haven and London.

Thiem, A. (2015). Parameters of fit and intermediate solutions in multi-value Qualitative Comparative Analysis. Qual. Quant., 49, 657-674.

Upadhaya, S., Arbuckle, J.G. \& Schulte, L.A. (2021). Developing farmer typologies to inform conservation outreach in agricultural landscapes. Land use policy, 101, 105157.

USDA. (2017). 2017 Census of Agriculture, State Profile: Maryland.

Venter, Z.S., Jacobs, K. \& Hawkins, H.-J. (2016). The impact of crop rotation on soil microbial diversity: A meta-analysis. Pedobiologia (Jena)., 59, 215-223.

Vogl, S., Parsons, J.A., Owens, L.K. \& Lavrakas, P.J. (2019). Experiments on the Effects of Advance Letters in Surveys. In: Exp. Methods Surv. Res. Tech. that Comb. Random Sampl. with Random Assign. (eds. Lavrakas, P.J., Traugott, M.W., Kennedy, C., Holbrook, A.L., de Leeuw, E.D. \& West, B.T.). John Wiley \& Sons, Inc, New Jersey, pp. 89-110.

Wallander, S., Smith, D., Bowman, M. \& Claassen, R. (2021). Cover Crop Trends, Programs, and Practices in the United States. Econ. Inf. Bull. USDA ERS, 222.

Wang, T., Jin, H., Kreuter, U., Feng, H., Hennessy, D.A., Teague, R. \& Che, Y. (2020). Challenges for rotational grazing practice: Views from non-adopters across the Great Plains, USA. J. Environ. Manage., 256, 109941.

Zeweld, W., Huylenbroeck, G. Van, Tesfay, G. \& Speelman, S. (2017). Smallholder farmers' behavioural intentions towards sustainable agricultural practices. J. Environ. Manage., 187, 71-81.

Peer) reviewing PDF | (2021:05:61360:1:0:REVIEW 14 Jul 2021) 
Table $\mathbf{1}$ (on next page)

Description of conservation practices 
1 Table 1: Description of conservation practices

\begin{tabular}{|c|c|c|c|}
\hline $\begin{array}{l}\text { Production } \\
\text { Type }\end{array}$ & Conservation Practice & Description & Citation \\
\hline \multirow{3}{*}{ Livestock } & Stream exclusion fencing & $\begin{array}{l}\text { Livestock are prevented from entering streams by } \\
\text { fences to reduce stream bank erosion and } \\
\text { deposition of animal waste in the water }\end{array}$ & $\begin{array}{l}\text { Bragina et al. } \\
(2017)\end{array}$ \\
\hline & $\begin{array}{l}\text { Rotational } \\
\text { grazing/pasture } \\
\text { management }\end{array}$ & $\begin{array}{l}\text { Livestock are frequently moved between paddocks } \\
\text { to prevent them from using other parts of the } \\
\text { pasture while biomass regenerates }\end{array}$ & $\begin{array}{l}\text { Sovell et al. } \\
(2000)\end{array}$ \\
\hline & Manure storage facility & $\begin{array}{l}\text { Manure is stored securely in concrete structures to } \\
\text { prevent waste runoff, especially during rainy } \\
\text { weather }\end{array}$ & $\begin{array}{l}\text { Meals \& } \\
\text { Braun (2006) }\end{array}$ \\
\hline \multirow{4}{*}{ Crops } & Cover crops & $\begin{array}{l}\text { Crops planted either to cover soil between rows or } \\
\text { across fields during the off-season to retain soil } \\
\text { nutrients and prevent surface runoff }\end{array}$ & $\begin{array}{l}\text { Dabney et al. } \\
(2001)\end{array}$ \\
\hline & Conservation tillage & $\begin{array}{l}\text { Various techniques to reduce soil disturbance } \\
\text { during planting and harvesting to prevent erosion }\end{array}$ & $\begin{array}{l}\text { Holland } \\
(2004)\end{array}$ \\
\hline & Crop rotation & $\begin{array}{l}\text { Plots are planted with different crops across } \\
\text { growing seasons to increase soil microbial diversity } \\
\text { and control pests }\end{array}$ & $\begin{array}{l}\text { Venter et al. } \\
(2016)\end{array}$ \\
\hline & Variable rate application & $\begin{array}{l}\text { The rate of seed, pesticide, and fertilizer } \\
\text { application is altered depending on specific } \\
\text { attributes of the field, potentially reducing overall } \\
\text { nutrient inputs }\end{array}$ & $\begin{array}{l}\text { Fleming et al. } \\
(2000)\end{array}$ \\
\hline
\end{tabular}




\section{Figure 1}

Figure 1: Bar charts showing variation among interview respondents.

Top panels show rates of conservation practice adoption among livestock producers $(A ; N=$ 52 and crop producers $(B ; N=81)$. Middle panels show farm products produced by livestock producers (C) and crop producers (D). Lower panels show frequency of attended outreach events in 2019 for livestock producers (E) and crop producers (F). 
(A)
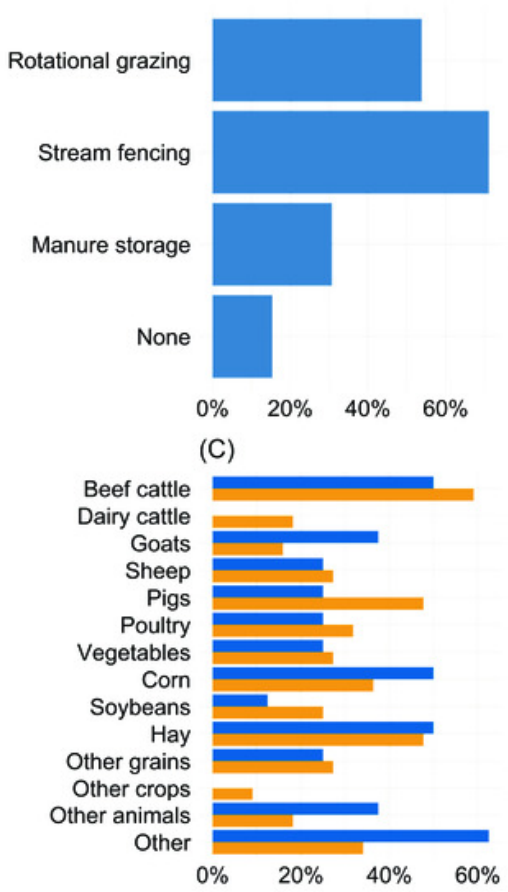

$(\mathrm{E})$

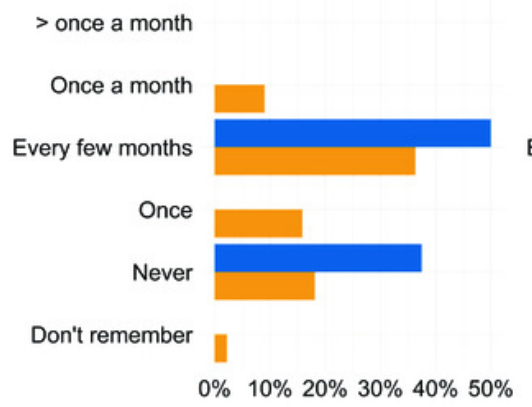

(B)
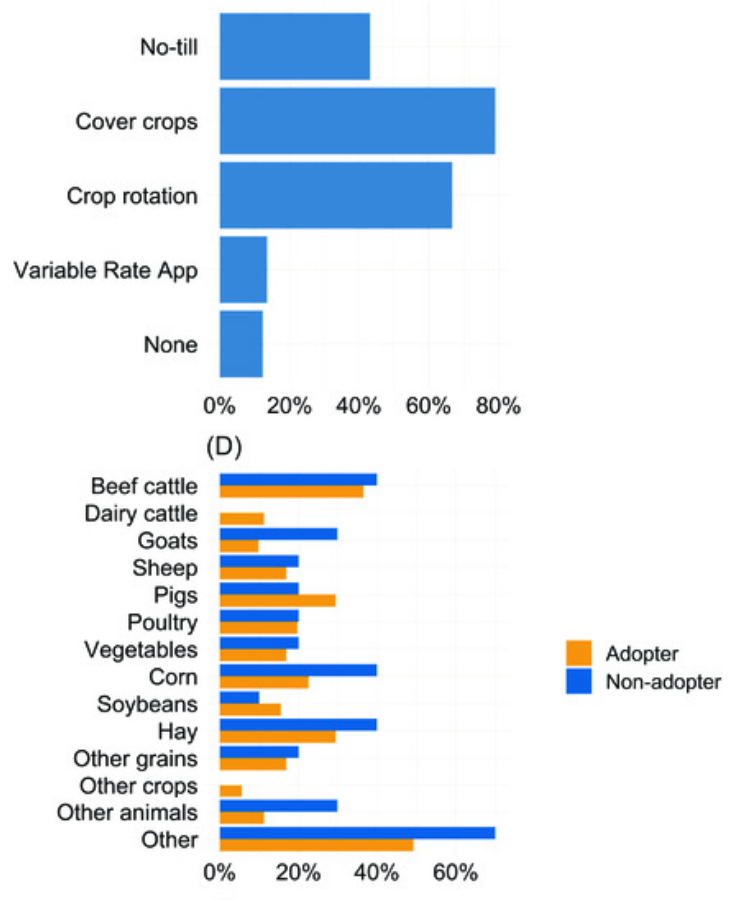

(F)

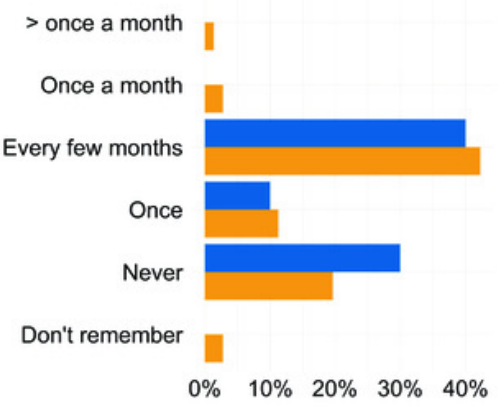

Figure 1: Bar charts showing variation among interview respondents. Top panels show rates of conservation practice adoption among livestock producers $(A ; N=52$ and crop producers $(B ; N=81)$. Middle panels show farm products produced by livestock producers (C) and crop producers (D). Lower panels show frequency of attended outreach events in 2019 for livestock producers $(\mathrm{E})$ and crop producers $(\mathrm{F})$. 
Figure 2

Figure 2: Differences in how adopters and non-adopters filter advertisements they receive for outreach events. 


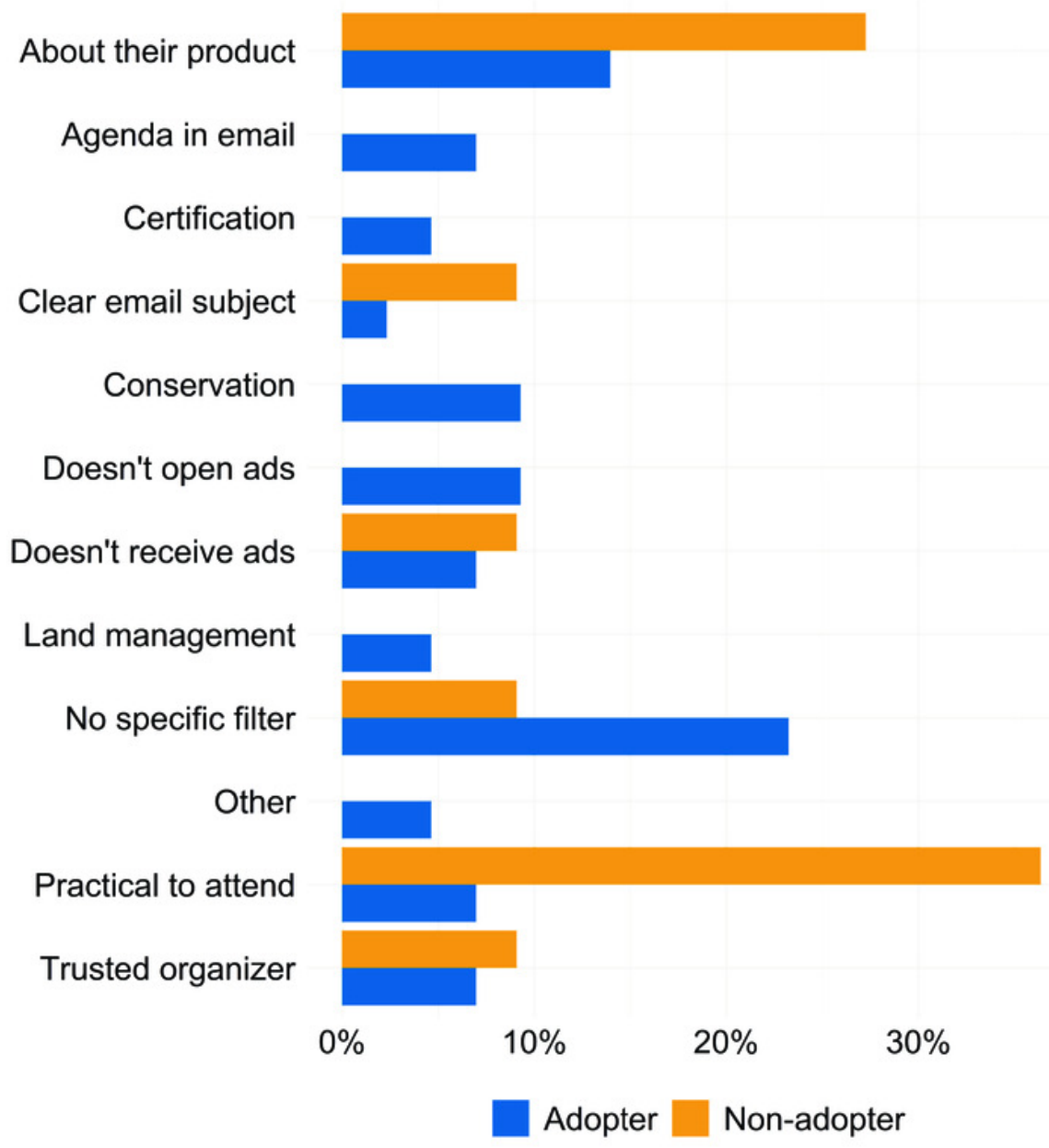

Figure 2: Differences in how adopters and non-adopters filter advertisements they receive for outreach events. 


\section{Figure 3}

Figure 3: Pathways for non-adopters (top) and adopters (bottom) of livestock-related conservation practices who reported attending at least one outreach event.

Each pathway (rows) represents one combination of conditions. That is, the two boxes in the first row indicate that if someone reported attending an event lasting 2-4 hours and that was on a weekend, then that respondent will be a non-adopter of livestock-related conservation practices. The consistency (consS) and coverage (covS) of sufficiency scores for each pathway, as well as the number of cases (respondents) whom this pathway describes, are shown in columns on the right. The scores for the full solution are presented at the bottom. 

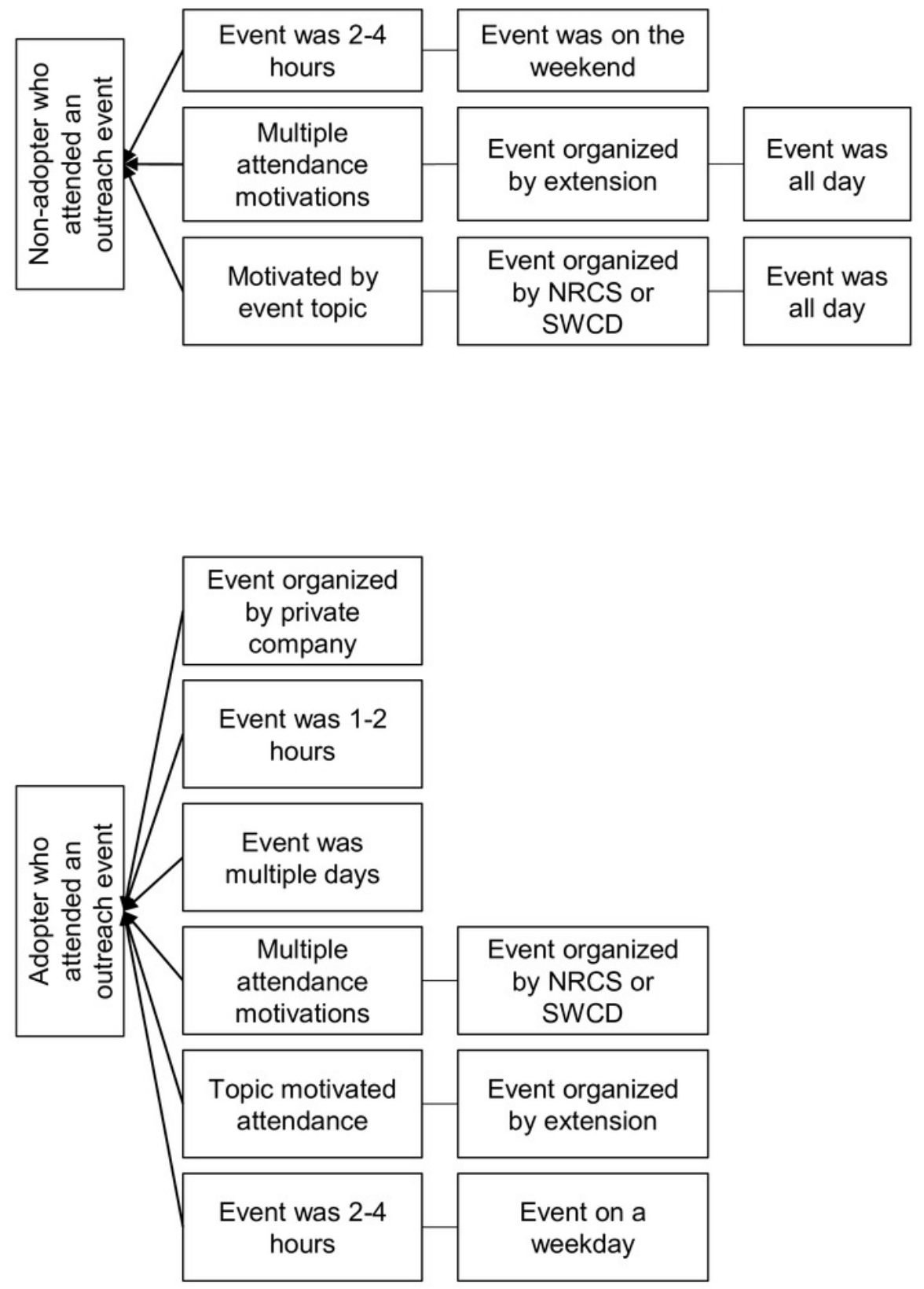

conss covs \# Cases

$\begin{array}{lll}1.000 & 0.250 & 1\end{array}$

1.0000 .5002

$1.000 \quad 0.250 \quad 1$

1.0001 .0004

consS covs \#Cases

1.0000 .1716

$1.000 \quad 0.2298$

$1.000 \quad 0.1435$

$1.000 \quad 0.1716$

$1.000 \quad 0.143 \quad 5$

$1.000 \quad 0.2579$

$1.000 \quad 0.914 \quad 35$ 
Figure 4

Figure 4: Pathways for non-adopters (top) and adopters (bottom) of crop-related conservation practices who reported attending at least one outreach event.

See Figure 3 caption for interpretation. 

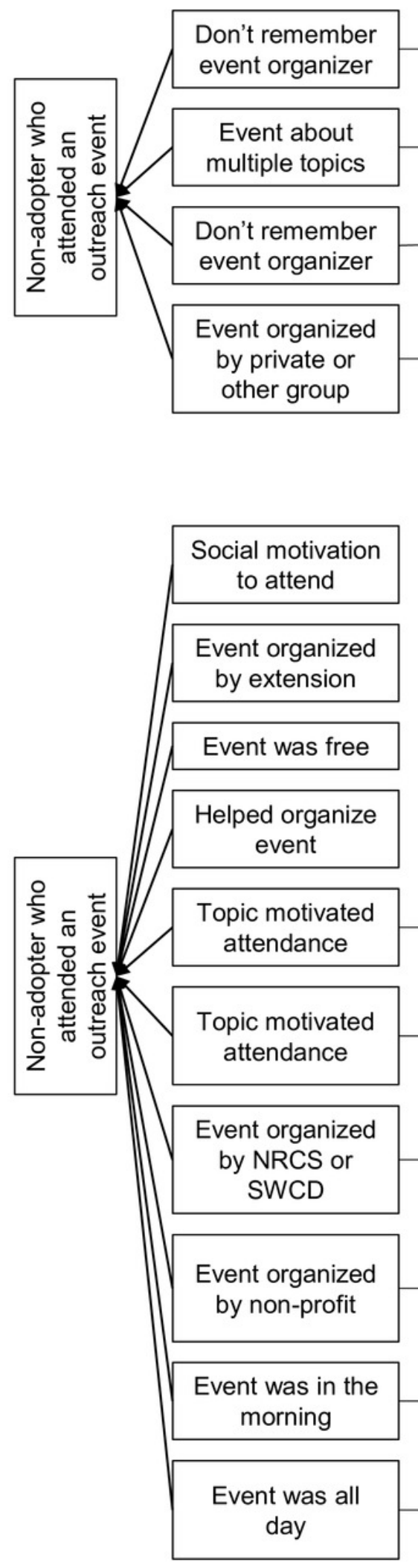

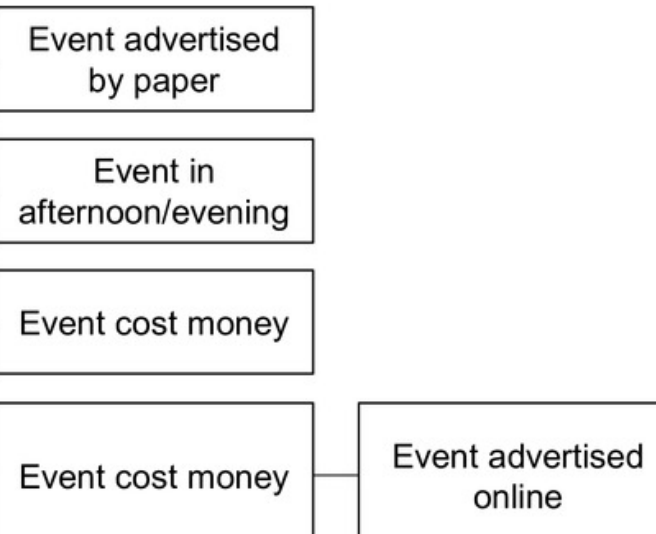

online conss $\underline{\text { covs }}$ \#Cases

$\begin{array}{lll}1.000 & 0.143 & 1\end{array}$

$\begin{array}{lll}1.000 & 0.143 & 1\end{array}$

$\begin{array}{lll}1.000 & 0.143 & 1\end{array}$

$1.000 \quad 0.2862$

$1.000 \quad 0.7145$

conss covs \#Cases

$1.000 \quad 0.0181$

$\begin{array}{lll}1.000 & 0.321 & 18\end{array}$

$\begin{array}{lll}1.000 & 0.232 & 13\end{array}$

$1.000 \quad 0.071 \quad 4$

$1.000 \quad 0.1257$ topics

Don't remember how it was advertised

$1.000 \quad 0.143 \quad 8$

Event about conservation

$1.000 \quad 0.071 \quad 4$

Event about agricultural land management

$1.000 \quad 0.0181$

$1.000 \quad 0.1257$

weekend

Didn't know others attending beforehand
$1.000 \quad 0.0714$

$1.000 \quad 0.87549$ 
Table 2 (on next page)

The conditions and their calibration as used in the study 
1 Table 2: The conditions and their calibration as used in the study

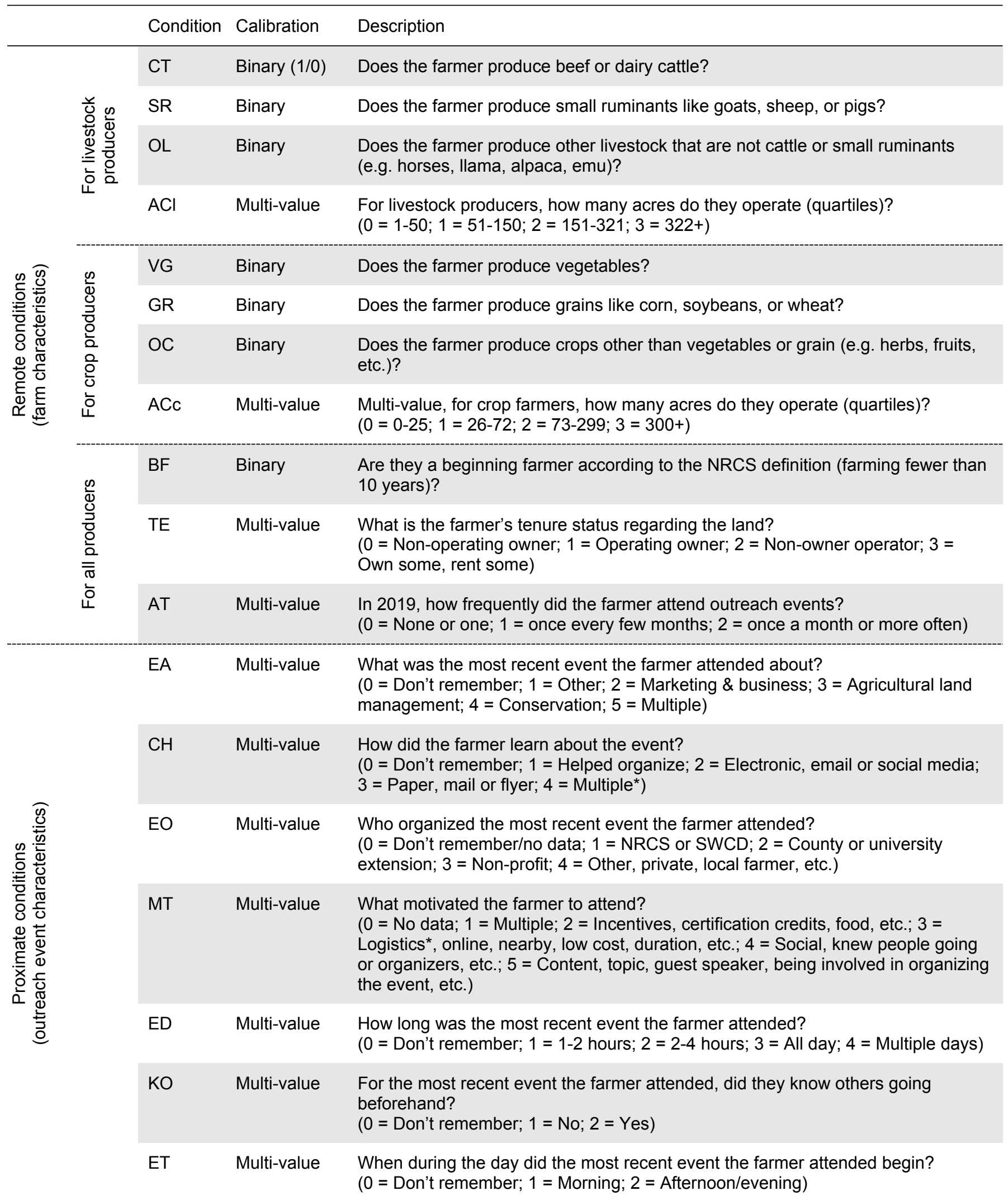




EC Multi-value Was there a cost associated with the most recent event the farmer attended?

WK Multi-value Was the most recent event the farmer attended on the weekday or weekend? ( 0 = Don't remember; 1 = No; 2 = Yes)

* These values did not appear in the data

3

4 